\title{
(C) OPEN ACCESS \\ Spiritual care provided by nursing home physicians: a nationwide survey
}

\section{Marie-José H E Gijsberts, ${ }^{\oplus}$ Jenny T van der Steen, ${ }^{2}$ Cees M P M Hertogh, ${ }^{3}$ Luc Deliens $^{4,5}$}

\begin{abstract}
${ }^{1}$ End-of-Life Care Research Group, Vrije Universiteit Brussel and Ghent University, Brussels, Belgium

${ }^{2}$ Public Health and Primary Care, Leids Universitair Medisch Centrum, Leiden, Netherlands ${ }^{3}$ General Practice \& Elderly Care Medicine, VU University Medical Center, Amsterdam, Netherlands ${ }^{4}$ End of Life Care Research Group, Vrije Universiteit Brussel, Brussels, Belgium

${ }^{5}$ Medical Oncology, Ghent University Hospital, Ghent, Belgium
\end{abstract}

\section{Correspondence to}

Dr Marie-José H E Gijsberts, End-of-Life Care Research Group, Vrije Universiteit Brussel \& Ghent University, Brussels 1090 Belgium;

Marie-Jose.Gijsberts@vub.be

Received 11 January 2019 Revised 3 March 2019 Accepted 13 March 2019

\section{Check for updates}

(c) Author(s) (or their employer(s)) 2019. Re-use permitted under CC BY-NC. No commercial re-use. See rights and permissions. Published by BMJ.

To cite: Giisberts M-JHE, van der Steen JT, Hertogh CMPM, et al. BMJ Supportive \& Palliative Care Epub ahead of print: [please include Day Month Year]. doi:10.1136/ bmjspcare-2018-001756

\section{ABSTRACT}

Objective To examine perceptions and experiences regarding providing spiritual care at the end of life of elderly care physicians practising in nursing homes in the Netherlands, and factors associated with spiritual care provision.

Methods A cross-sectional survey was sent to a representative sample of 642 elderly care physicians requesting information about their last patient who died and the spiritual care they provided. We compared their general perception of spiritual care with spiritual and other items abstracted from the literature and variables associated with the physicians' provision of spiritual care. Self-reported reasons for providing spiritual care were analysed with qualitative content analysis.

Results The response rate was $47.2 \%$. Almost half (48.4\%) provided spiritual end-of-life care to the last resident they cared for. Half (51.8\%) identified all 15 spiritual items, but 95.4\% also included psychosocial items in their perception of spirituality and $49.1 \%$ included other items. Physicians who included more non-spiritual items reported more often that they provided spiritual care, as did more religious physicians and those with additional training in palliative care. Reasons for providing spiritual care included a request by the resident or the relatives, resident's religiousness, fear of dying and involvement of a healthcare chaplain.

Conclusion Most physicians perceived spirituality as a broad concept and this increased self-reported spiritual caregiving. Religious physicians and those trained in palliative care may experience fewer barriers to providing spiritual care. Additional training in reflecting upon the physician's own perception of spirituality and training in multidisciplinary spiritual caregiving may contribute to the quality of end-of-life care for nursing home residents.

\section{INTRODUCTION}

The spiritual dimension is the least developed dimension of palliative care. ${ }^{1}$ The concept of spirituality is complex, which is a hindrance to spiritual caregiving at the end of life. ${ }^{2}$ Patients often experience spiritual distress at the end of life, and alleviation of spiritual distress contributes to spiritual and psychosocial well-being, ${ }^{3-5}$ and improves quality of life and quality of care. ${ }^{67}$

In the USA, UK and the Netherlands about a quarter of all older people die in nursing homes. ${ }^{8}{ }^{9}$ An international study in over 21 countries showed that almost a fifth of all deaths of older people occur in nursing homes. ${ }^{10}$ Older nursing home residents have emphasised the importance of spirituality and spiritual care at the end of life, ${ }^{11}$ and spiritual caregiving by nursing home staff is related to a better family evaluation of end-of-life care for nursing home residents. ${ }^{12}$ Spiritual caregiving in dementia is considered especially difficult. An ethnographic study in a Dutch nursing home showed that spiritual issues in residents with and without dementia were only informally addressed by nursing staff. ${ }^{13}$ The European Association for Palliative Care published a white paper on palliative care in dementia and recommends assessment of religious affiliation, referral to an experienced healthcare chaplain and religious activities such as rituals, songs and services, if appropriate. $^{14}$

In the Netherlands on-staff elderly care physicians regularly provide end-of-life care to residents in nursing homes. ${ }^{15}{ }^{16} \mathrm{In}$ most Dutch nursing homes the physician is also responsible for the contents of the resident's care plan, which should include all the needs of the resident. ${ }^{17}$ Most nursing homes have on-staff healthcare chaplains and psychologists. In a focus group study 
with Dutch elderly care physicians, ${ }^{18}$ participants underlined the importance of distinguishing spiritual needs from psychosocial needs. However, we have no representative data on how physicians define spiritual issues as distinct from psychosocial issues and when they provide spiritual care.

In this study we examine Dutch elderly care physicians' perceptions of spirituality and of provision of spiritual care at the end of life, and factors associated with provision of spiritual end-of-life care.

\section{METHODS}

\section{Design}

We performed a cross-sectional survey among a representative sample of practising Dutch elderly care physicians who generally practise in long-term care, mostly nursing homes. We aimed at a few hundred cases available for exploratory regression analyses. A postal questionnaire was sent to half $(n=642)$ of the 1248 elderly care physicians registered at Verenso (the Dutch Association of Elderly Care Physicians and Social Geriatricians, where most elderly care physicians are registered), sampling alternately in alphabetical order of last names. The questionnaire was sent out in October 2012 and one reminder was sent to non-responders in November 2012. We received completed questionnaires until February 2013.

The Medical Ethics Review Committee of the VU University Medical Centre approved this survey as part of a larger study protocol that comprised a series of studies on 'Spiritual care at the end of life in Dutch nursing homes'.

\section{Questionnaire}

The provision of spiritual care at the end of life was measured using the question: 'In your opinion, did you provide spiritual care to the last resident you cared for in the last month of life?' We also asked: 'Did you differentiate between psychosocial and spiritual needs in this resident?'

We measured the perception or knowledge of spiritual care through item identification by the physicians from a mixed list of 30 items with 'right' (validated spiritual care) items and 'wrong' items (validated for relationship with other concepts). The 30 items were introduced with: 'In your opinion, spirituality at the end of life may comprise: ...', inviting respondents to include any number of items they perceived as being part of spirituality at the end of life. Based on a literature review of instruments measuring spirituality at the end of life, ${ }^{19}$ we selected 15 items with content validity regarding spirituality ('right'), such as items on spiritual well-being, spiritual beliefs and activities, and spiritual coping. ${ }^{20-25}$ Fifteen additional non-spiritual items ('wrong') were drawn from validated instruments measuring quality of life at the end of life. ${ }^{2022425}$ Ten of these non-spiritual items concerned psychosocial needs and five items addressed other issues (physical needs, medical/communicational, financial).

Additionally, if the elderly care physician did not provide spiritual care, the questionnaire assessed the reasons for not providing spiritual care with a semi-structured question including the answers 'lack of training', 'lack of time', 'quality of the relationship between the physician and the patient' (they had known the patient only for a short time) and an openended option 'other'. In the latter case, the physician could give other specific reasons. Another open-ended item in the questionnaire was included in this study: 'Were there indications the nursing home resident had spiritual needs?' If the participant answered 'yes', the open-ended question was: 'what indication(s)?'

Physician and practice characteristics were also part of the questionnaire. We measured religiousness with the Religious and Spiritual Beliefs and Practices Scale, ${ }^{26}$ a validated and self-administered tool with five questions previously used to measure religiousness of US general practitioners. Sum scores range from 5 to 21. We pilot tested an earlier version of the questionnaire among five elderly care physicians and improved the questionnaire based on their responses and comments specifically concerning user friendliness and clarity of the questionnaire.

\section{Analyses}

We analysed non-response by comparing geographical distributions of respondents and non-respondents. We described the proportion of physicians who felt they provided spiritual care at the end of life, their differentiation between spiritual and non-spiritual items, and the physicians' perceptions of spirituality at the end of life with proportions of the respondents that included the 30 items as belonging to spirituality at the end of life. We quantified the degree to which their perception of spirituality at the end of life corresponded with measurable and validated aspects of spirituality at the end of life in the literature in three ways. First, we counted the number included of the 15 items that represented the literature on spirituality at the end of life. Second, we counted the number of non-spiritual items included that represented the non-spiritual aspects of quality of life at the end of life. Third, we calculated how close the physician's perception was to the literature by subtracting the number of the 15 non-spiritual items the physicians included as belonging to spirituality from the number of the 15 spiritual items they included. Thus, a total score of +15 referred to complete consistency with the literature and a total score of -15 referred to a complete opposite perception of spirituality, and a mean score of 0 was expected with random endorsing of items. We considered scores of +8 and higher (a minimum mean of +7.5 , at least midway 0 and 15 ) to be reasonably consistent with the literature. 
We imputed with item means if, at most, one of the five items of the Religious Beliefs and Practices Scale was missing, resulting in complete scores for all but two physicians. Very few data were missing overall, and we kept five questionnaires with missing outcomes in the descriptive analyses only. Multivariable logistic regression was used to determine associations between the physicians' perception of spirituality as the independent variable and provision of spiritual end-of-life care as the dependent variable, adjusted for physicians' characteristics. We also adjusted for the total number of included items to avoid any influence of physicians possibly including (all) items unselectively. We tested interaction terms between the independent variable of interest and any physician characteristic significantly associated with the outcome. If needed in the multivariable regression, we imputed with mode or mean where appropriate. We calculated odds ratios (OR) and $95 \%$ confidence intervals. Data were analysed using SPSS 20.0.0 (IBM Statistics, 2011). The qualitative data (responses to the open-ended items) were analysed by content analysis (M-JHEG and JTvdS).

\section{RESULTS}

The response rate was 47.2\% (303/642 physicians), with no selective response for different geographical regions (provinces). Of the respondents, 19 were no longer practising physicians and were excluded, resulting in a sample of 284 cases for analysis.

Table 1 shows the characteristics of the physicians. The mean age was 46.7 years and $66.0 \%$ were female. A small minority $(10.7 \%)$ had had additional training in palliative care. Over half (56.9\%) of the participants had no current denomination. The mean (SD) of the religiosity scale was 11.5 (4.4). Almost half (48.4\%) of the physicians felt they had provided spiritual care to the last patient they attended at the end of life. Of these patients, $38.5 \%$ had dementia.

Over half (55.2\%) of the physicians stated that there were indications that the resident had spiritual needs, and almost all of them explained such indications.

Some indications concerned the way conversations on spiritual needs were initiated and by whom (the residents, relatives or the physician). For example,

- "(The resident) expressed the need to talk to me about spiritual issues".

- Relatives: "Her family told me that she (the resident) had lived in a monastery as a nun".

Physicians also initiated conversations, for example:

- "[I] asked actively about wishes concerning the resident's philosophy of life (and) important issues".

Other indications concerned reasons to provide spiritual care:

- Issues concerning spiritual well-being were discussed, such as meaning, purpose, acceptance of death and completion of life: "(Resident) expressed in conversations the need to take stock of his life" or "Letting go, accepting (his death)" or "(He told me) he was at peace with dying soon".
Table 1 Demographics of physicians and characteristics of nursing homes

\begin{tabular}{|c|c|c|c|}
\hline \multicolumn{4}{|c|}{ Physicians } \\
\hline \multicolumn{2}{|c|}{ Age, mean (SD) } & \multicolumn{2}{|c|}{$46.7(9.5)$} \\
\hline \multicolumn{2}{|c|}{ Female, \% } & \multicolumn{2}{|l|}{66.0} \\
\hline \multicolumn{4}{|c|}{ Additional training, $\%$} \\
\hline$\triangleright$ & Geriatric rehabilitation & \multicolumn{2}{|l|}{26.0} \\
\hline$\triangleright$ & Psychogeriatric & \multicolumn{2}{|l|}{7.5} \\
\hline$\triangleright$ & Palliative care & \multicolumn{2}{|l|}{6.0} \\
\hline$\triangleright$ & Ethics & \multicolumn{2}{|l|}{2.5} \\
\hline \multicolumn{2}{|c|}{$\begin{array}{l}\text { Years specialisation elderly care physician, } \\
\text { mean (SD) }\end{array}$} & \multicolumn{2}{|c|}{$12.7(8.4)$} \\
\hline \multicolumn{4}{|c|}{ Current religion/Religious background, \% } \\
\hline$>$ & Roman Catholic & 10.3 & 41.8 \\
\hline$\triangleright$ & Protestant & 13.9 & 30.1 \\
\hline$\triangleright$ & Evangelical & 1.4 & 1.4 \\
\hline$\triangleright$ & Jewish & 0.0 & 0.0 \\
\hline$\triangleright$ & Islamic & 0.7 & 1.1 \\
\hline 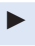 & Humanistic & 2.5 & 1.8 \\
\hline$\triangleright$ & Buddhist & 0.7 & 0.7 \\
\hline$\triangleright$ & Atheist & 4.6 & 3.9 \\
\hline$\triangleright$ & Agnostic & 2.1 & 0.4 \\
\hline$\triangleright$ & None & 54.8 & 12.8 \\
\hline$\triangleright$ & Other, such as Hindu, or several religions & 8.9 & 6.0 \\
\hline & $\begin{array}{l}\text { ous and Spiritual Beliefs and Practices } \\
\text { summed score }\end{array}$ & 11.5 & \\
\hline
\end{tabular}

About how often do you attend religious or spiritual services?

$\begin{array}{lr}\text { Daily } & 0.4 \\ \text { Weekly } & 13.2 \\ \text { Monthly } & 13.2 \\ \text { Once a year } & 29.5 \\ \text { Not at all } & 43.8\end{array}$

About how often do you spend time in private religious or spiritual practices?

$\begin{array}{ll}\text { Daily } & 24.3 \\ \text { Weekly } & 15.4 \\ \text { Monthly } & 16.4 \\ \text { Once a year } & 15.7 \\ \text { Not at all } & 28.2\end{array}$

How strongly religious (or spiritually

orientated) do you consider yourself?

\begin{tabular}{ll} 
Not at all & 15.2 \\
Not very strong & 15.2 \\
Strongewhat strong & 46.1 \\
\hline
\end{tabular}

How often have you felt as though you were very close to a powerful spiritual force that seemed to lift you outside yourself?

\begin{tabular}{lr} 
- & \\
- Several times & 6.8 \\
- Once or twice & 21.8 \\
Never & 17.9 \\
\hline
\end{tabular}

How close do you feel to God (or a Higher Force)?

- Extremely close 6.4 


\begin{tabular}{|c|c|c|}
\hline \multicolumn{3}{|c|}{ Physicians } \\
\hline$\triangleright$ & Somewhat close & 22.5 \\
\hline$\triangleright$ & Not very close & 36.8 \\
\hline$\triangleright$ & I don't believe in God & 34.3 \\
\hline \multicolumn{3}{|c|}{ Nursing homes } \\
\hline \multicolumn{3}{|c|}{ Religious affiliation nursing home, \% } \\
\hline$\triangleright$ & Roman Catholic & 16.3 \\
\hline$\triangleright$ & Protestant & 9.2 \\
\hline$\triangleright$ & Humanistic & 2.1 \\
\hline$\triangleright$ & Antroposophic & 0.7 \\
\hline$\triangleright$ & Buddhist & 0.0 \\
\hline$\triangleright$ & None & 58.9 \\
\hline 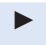 & Other & 12.8 \\
\hline \multicolumn{3}{|c|}{$\begin{array}{l}\text { Disciplines to refer to when resident has } \\
\text { spiritual needs, \% }\end{array}$} \\
\hline$\triangleright$ & Spiritual counsellor & 93.2 \\
\hline$\triangleright$ & Humanistic counsellor & 16.0 \\
\hline$\triangleright$ & Psychologist & 88.3 \\
\hline & $\begin{array}{l}\text { Nurse specialised in social and psychiatric } \\
\text { eeds (SPV) }\end{array}$ & 8.9 \\
\hline$\triangleright$ & Imam & 4.6 \\
\hline$\triangleright$ & Pandit & 1.1 \\
\hline$\triangleright$ & None & 1.8 \\
\hline
\end{tabular}

In region of nursing home religious background is predominantly, \%

$\begin{array}{lr}\text { (Roman) Catholic } & 69.9 \\ \text { Protestant } & 69.9 \\ \text { Evangelical } & 2.5 \\ \text { Jewish } & 1.8 \\ \text { Islamic } & 8.7 \\ \text { Humanistic } & 5.1 \\ \text { Auddhist } & 1.8 \\ \text { Agnostic } & 7.6 \\ \text { Our religious background } & 2.9 \\ \text { Our nursing home has experience in } & 18.8 \\ \text { providing spiritual care to Muslim residents, } & \\ \text { \% } & \end{array}$

Our nursing home has experience in 78.3 providing spiritual care to residents with dementia, \%

Our nursing home created the following conditions to provide spiritual care

The right atmosphere in the nursing home
to provide spiritual care
$\quad$ Meditation room
Pufficient capacity of the following disciplines
(more answers possible, \% of those who
indicated sufficient capacity):
$\begin{aligned} & \text { Spiritual counsellor } \\ & \quad \text { Physicians }\end{aligned}$
$\quad$ Nursing staff
$\quad$ Psychologists
$\quad$ Other, such as rituals, music therapy,
aroma therapy

- Religious needs were also a reason to provide spiritual care, for example: "(Resident expressed) wish to receive the last sacraments", "The family had called for their priest themselves".

- Spiritual distress also indicated a need for spiritual care: "I discussed this (fear of the end of life) with her from the perspective of her specific wish/feeling to 'be able to find peace', to 'deal with unfinished business' and the inevitable". Sometimes, however, the distress was typically psychological or possibly social in nature: "Fear, an enormous need to have people around him" or "Restlessness, longing for his wife and his own home".

Of the physicians who reported that they did not provide spiritual care $(51.6 \%), 26.4 \%$ stated that they did not do so because of lack of training, $22.9 \%$ because of lack of time and $11.8 \%$ because they had known the patient only for a short time. At the open question 'other reasons', 69.4\% $(n=108)$ mentioned one or more of the following reasons: spiritual care was already provided by other discipline or organised by family $(n=21)$, difficulty in communication with the resident $(n=19)$, dementia $(n=18)$, the patient had no spiritual needs $(n=18)$, there was a rapid decline in health $(n=16)$, did not consider to do provide spiritual care/did not know how to do so $(n=9)$, not the physician's responsibility $(n=6)$.

Table 2 shows the 30 items ranked by the number of physicians who included the items as belonging to spirituality at the end of life. It shows that all items included by more than $90 \%$ of the physicians (rank numbers 1-13 in table 2) represented measurable and validated aspects of spirituality at the end of life. Of the items consistent with the spirituality literature, the least frequently included item concerned feeling disconnected (number 20); yet $73.4 \%$ of the physicians did include it. Further, almost all (95.4\%) included one or more psychosocial items in their perception of spirituality and $49.1 \%$ included at least one item on other issues.

Over half (51.8\%) of the physicians included all 15 items that represented measurable and validated aspects of spirituality in the literature (figure 1). Furthermore, most others included almost all, the mean (SD) number being 13.8 (1.8) of 15 items. Nevertheless, most physicians were selective as only $4.9 \%$ included all 30 items. However, only $4.8 \%$ of the physicians did not additionally endorse any non-spiritual (quality-of-life) item, with a mean number of 8.3 such items additionally included and with a larger SD of 4.3. The mean total score for consistency with the literature was therefore 5.5 (13.8 minus 8.3), and ranged between -7 and +14 (SD 3.9) (figure 2). Over half $(54.3 \%)$ of the physicians indicated that they did not differentiate between spiritual and psychosocial needs in caring for the last resident who died. Physicians who did not differentiate between these needs indeed included a somewhat higher number of non-spiritual items in their perception: mean (SD) 8.9 (4.3) vs 7.5 


\begin{tabular}{|c|c|c|c|c|}
\hline $\begin{array}{l}\text { Rank } \\
\text { no }\end{array}$ & Item (n=284) & Endorsed (\%) & Missing* (n) & $\begin{array}{l}\text { Spiritual +/ non- } \\
\text { spiritual - }\end{array}$ \\
\hline 1 & Being supported by religion ${ }^{20}$ & 98.9 & 0 & $\begin{array}{l}+ \\
\text { S-CT-S-C }\end{array}$ \\
\hline 2 & Believing in a supreme power ${ }^{21}$ & 96.8 & 0 & $\begin{array}{l}+ \\
\mathrm{S}-\mathrm{CT}\end{array}$ \\
\hline 3 & | feel peacefu| $\left.\right|^{22}$ & 96.8 & 1 & $\begin{array}{l}+ \\
\text { S-WB }\end{array}$ \\
\hline 4 & Talking with someone about religious issues ${ }^{23}$ & 96.5 & 0 & $\begin{array}{l}+ \\
\mathrm{S}-\mathrm{CT}\end{array}$ \\
\hline 5 & Pray $^{23}$ & 96.5 & 0 & $\begin{array}{l}+ \\
\mathrm{S}-\mathrm{CT}\end{array}$ \\
\hline 6 & Believing in an afterlife ${ }^{21}$ & 95.4 & 1 & $\begin{array}{l}+ \\
\mathrm{S}-\mathrm{CT}\end{array}$ \\
\hline 7 & Feeling that one is protected by a higher power beyond oneself ${ }^{20}$ & 95.1 & 0 & $\begin{array}{l}+ \\
\text { S-CT }\end{array}$ \\
\hline 8 & It is important to me that my life has meaning ${ }^{24}$ & 94.0 & 0 & $\stackrel{+}{\text { S-WB }}$ \\
\hline 9 & Reading a religious text ${ }^{23}$ & 93.3 & 0 & $\stackrel{+}{\mathrm{S}-\mathrm{CT}}$ \\
\hline 10 & Dealing with unmet life goals ${ }^{25}$ & 92.9 & 1 & $\stackrel{+}{\text { S-WB }}$ \\
\hline 11 & Accepting your life situations ${ }^{21}$ & 92.2 & 1 & $\stackrel{+}{\text { S-WB }}$ \\
\hline 12 & In case of dying suddenly today, feeling prepared to leave this life ${ }^{24}$ & 90.5 & 0 & $\stackrel{+}{S-W B}$ \\
\hline 13 & Feeling that one's life was fulfilling ${ }^{20}$ & 90.1 & 1 & $\stackrel{+}{\text { S-WB }}$ \\
\hline 14 & Coping with feelings of sadness or grief ${ }^{25}$ & 85.9 & 0 & - \\
\hline 15 & Coping with feeling useless $s^{25}$ & 78.7 & 2 & - \\
\hline 16 & Having been able to say important things to those who are close $\mathrm{e}^{22}$ & $78.4^{\dagger}$ & 1 & $\begin{array}{l}+ \\
\text { S-WB }\end{array}$ \\
\hline 17 & Wanting to share what you are going through with another person ${ }^{25}$ & $78.4^{\dagger}$ & 1 & $\overline{\text { PS }}$ \\
\hline 18 & Dealing with feeling afraid ${ }^{25}$ & 78.3 & 3 & $\overline{\text { PS }}$ \\
\hline 19 & Coping with fears about losing your independence $e^{25}$ & 75.3 & 1 & $\overline{\text { PS }}$ \\
\hline 20 & Feeling more disconnected from all things now than before illness ${ }^{24}$ & 73.4 & 2 & $\stackrel{+}{S-W B}$ \\
\hline 21 & Dealing with feeling dependent on others ${ }^{25}$ & 66.5 & 0 & $\overline{\text { PS }}$ \\
\hline 22 & Coping with having difficulty relaxing ${ }^{25}$ & 65.6 & 2 & $\overline{-}$ \\
\hline 23 & Receiving emotional support from friends and family $y^{25}$ & 65.5 & 0 & $\overline{\text { PS }}$ \\
\hline 24 & Dealing with maintaining relationships with friends ${ }^{25}$ & 54.1 & 1 & $\overline{\text { PS }}$ \\
\hline 25 & Dealing with fears about the cancer spreading ${ }^{25}$ & 53.2 & 2 & $\overline{\text { PS }}$ \\
\hline 26 & Trusting your physician ${ }^{20}$ & 37.0 & 3 & Other \\
\hline 27 & Being involved with decisions about your medical treatment ${ }^{25}$ & 33.7 & 2 & Other \\
\hline 28 & Dealing with concerns about your financial situations ${ }^{25}$ & 21.6 & 2 & Other \\
\hline 29 & Getting adequate information from medical staff about your prognosis ${ }^{25}$ & 18.3 & 0 & Other \\
\hline 30 & Coping with nausea and vomiting ${ }^{25}$ & 16.5 & 0 & Other \\
\hline
\end{tabular}




\section{Table 2 Continued}

Rank

no Item $(\mathrm{n}=284)$

Spiritual +/ non-

Endorsed (\%) Missing* (n) spiritual -

,+ 15 items representing measurable and validated aspects of spirituality at the end of life in the literature $\left(^{+}\right.$reference 25 to literature in which item is validated).

,- 15 items representing other measurable and validated aspects at the end of life in the literature (quality of life, psychosocial needs, physical needs, communication) ( ${ }^{+}$reference to literature in which item is validated).

*Missing represents missing responses without comments or those with written comments such as 'do not know'.

${ }^{\dagger}$ Exactly the same frequency.

Other, physical, medical-communicational, financial; PS, psychosocial needs; S-C, spiritual coping; S-CT, spiritual cognitive behavioural context (spiritual beliefs, spiritual activities, spiritual relationships); S-WB, spiritual wellbeing (peace/harmony/trust/hope/acceptance, purpose/meaning, connectedness, completion/fulfilment, positive affect/comfort).

(4.2) $(\mathrm{p}=0.006)$ for physicians who indicated they did differentiate between these needs.

In view of the distributions of the item scores of spiritual (skewed) and non-spiritual items as described above and reflected in figure 1 , we used the number of included non-spiritual quality-of-life items as the independent variable in the multivariable logistic regression. Unadjusted, we found a significant association between selecting more non-spiritual items and the reported provision of spiritual end-of-life care (OR 1.17, 95\% CI 1.10 to 1.24 per additional item included). In adjusted analyses, the association remained significant and was stronger (OR 1.33, 95\% CI 1.11 to 1.60 per additional item; table 3). Further, more religious physicians were also more likely to report having provided spiritual end-of-life care (association with Spiritual Beliefs and Practice Scale: OR $1.09,95 \%$ CI 1.01 to 1.16 per point), as were those with additional training in palliative care (OR 5.0, 95\% CI 2.0 to 13). The association between the number of non-spiritual items included and having provided spiritual end-of-life care did not differ by the physicians' score on the Spiritual Beliefs and Practice
Scale (interaction term $\mathrm{p}=0.63$ ), nor by additional training in palliative care (interaction term $\mathrm{p}=0.37$ ). There was a modest correlation between the number of non-spiritual quality-of-life items included and religiosity $(\mathrm{r}=0.13, \mathrm{p}=0.03)$. There was no significant correlation between the number of non-spiritual items included and age, gender, additional training in palliative care, experience as a certified elderly care physician and no current religious denomination.

\section{DISCUSSION}

Dutch elderly care physicians practising in long-term care report providing spiritual care to almost half (48.4\%) of the patients who are at the end of life, giving attention to spiritual distress, religious issues and spiritual well-being. Their perception of spirituality included measurable and validated aspects of spirituality as reported in the literature, but overwhelmingly also included psychosocial aspects which the literature indicates as being non-spiritual quality-of-life issues: almost all (95.4\%) included one or more psychosocial items in their perception of spirituality, and 49.1\% included at least one other non-spiritual item

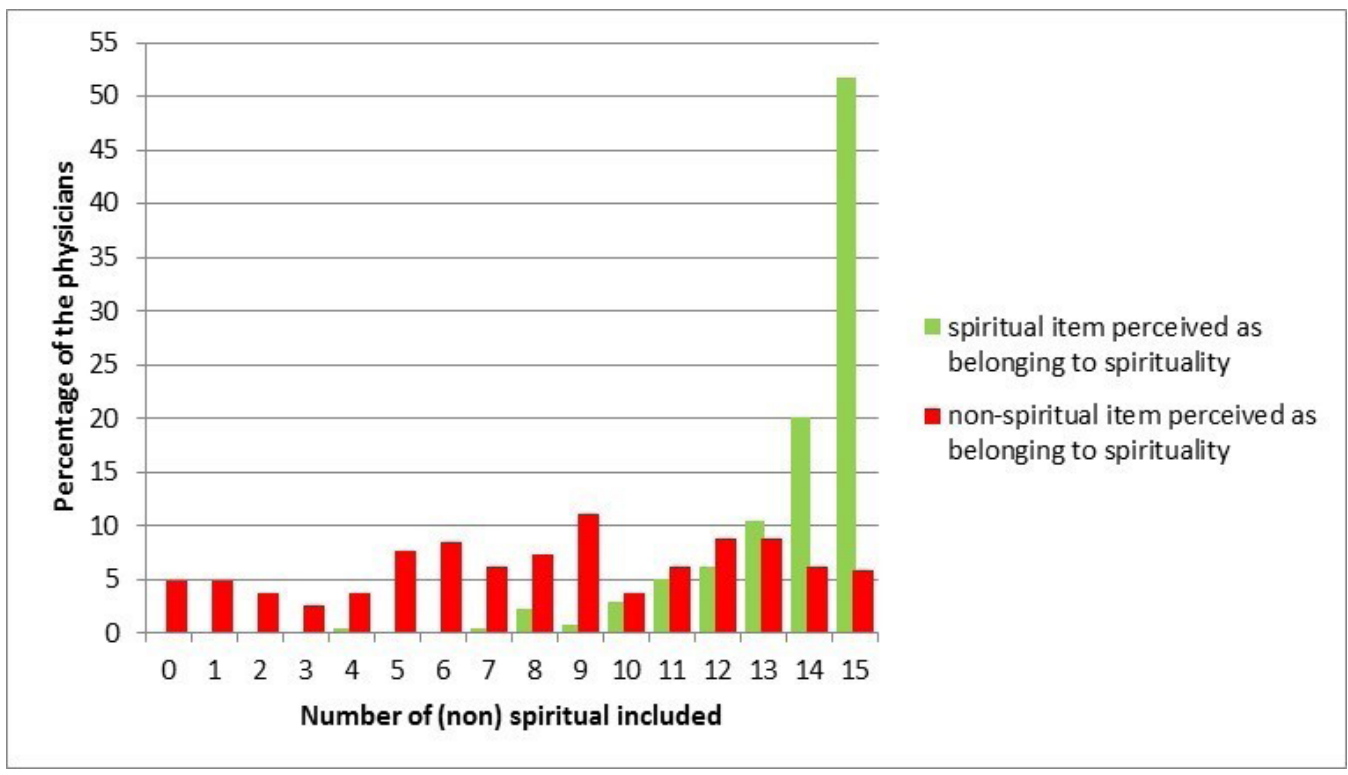

Figure 1 Number of spiritual and non-spiritual items included by physicians. 


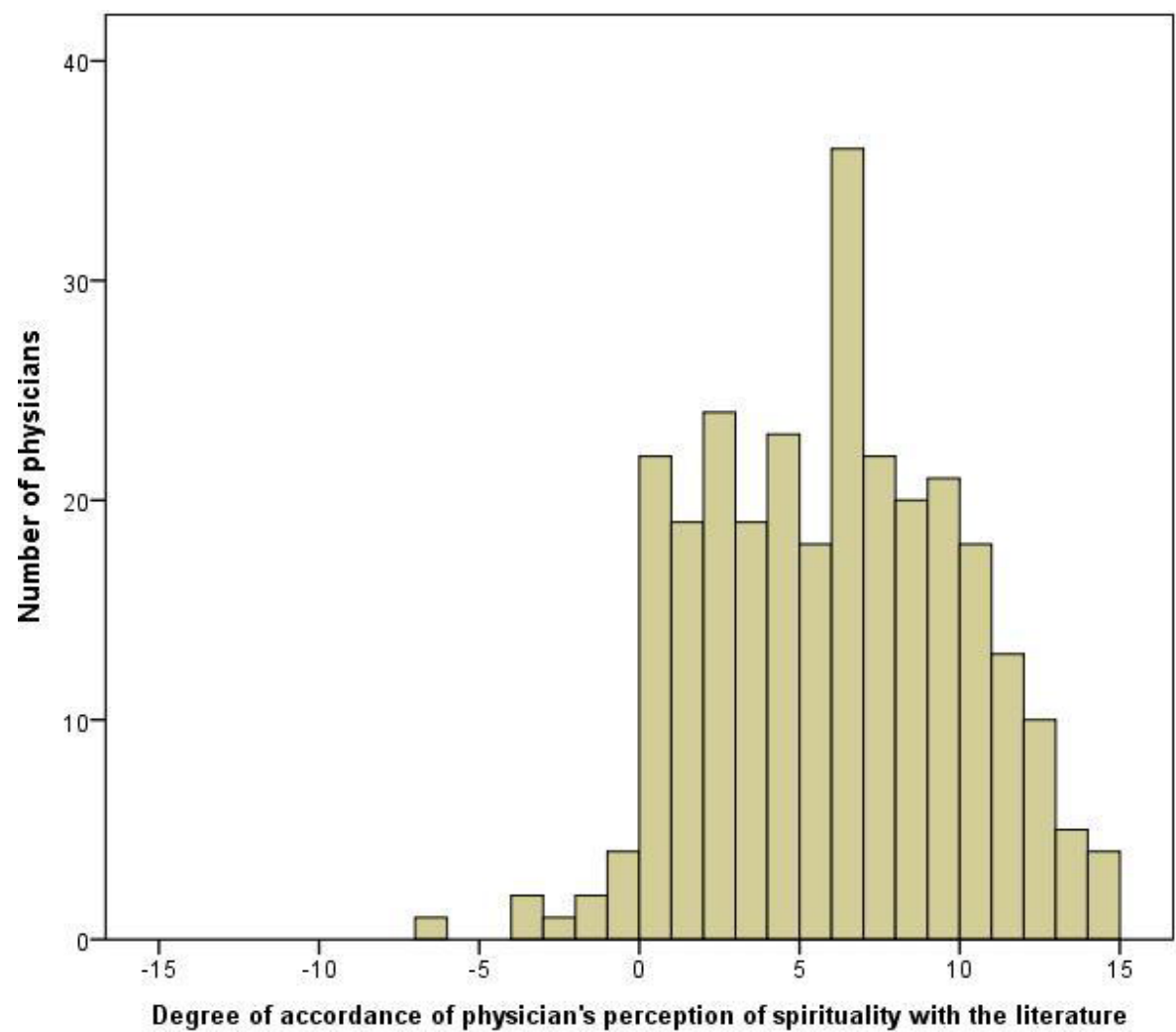

Figure 2 Score representing consistency of physician's perception of spirituality at the end of life with the literature. A score of +15 refers to a perception completely in accordance with the literature and -15 refers to a complete opposite perception of spirituality, while a score of 0 is expected with random endorsing of items.

(about physical, medical/communicational or financial aspects).

In a focus group study with Dutch elderly care physicians on spirituality and spiritual care at the end of life, the participants expressed the importance of distinguishing spiritual needs from psychosocial needs to adequately meet their needs. ${ }^{18}$ Rodin et al showed the complex relationship between the spiritual dimension (spiritual well-being) and the other dimensions of care at the end of life. ${ }^{27}$ They also underlined the importance

Table 3 Adjusted association between physicians' perception of spirituality and the provision of spiritual end-of-life care

\begin{tabular}{|c|c|c|}
\hline & OR & $95 \% \mathrm{Cl}$ \\
\hline \multicolumn{3}{|l|}{ Physicians' perception of spirituality } \\
\hline $\begin{array}{l}\text { Adjusted number of non-spiritual quality of life } \\
\text { items included as spiritual, per item }\end{array}$ & 1.33 & 1.11 to 1.60 \\
\hline \multicolumn{3}{|l|}{ Adjustments } \\
\hline Age & 1.00 & 0.96 to 1.05 \\
\hline Female gender & 0.93 & 0.52 to 1.67 \\
\hline Additional training in palliative care & 5.0 & 2.0 to 13 \\
\hline $\begin{array}{l}\text { Experience as a certified elderly care physician, } \\
\text { per year }\end{array}$ & 1.00 & 0.95 to 1.05 \\
\hline No current religious denomination & 0.77 & 0.42 to 1.4 \\
\hline $\begin{array}{l}\text { Religiosity, sum score on the Spiritual Beliefs and } \\
\text { Practices Scale, increment }\end{array}$ & 1.09 & 1.01 to 1.16 \\
\hline $\begin{array}{l}\text { Total number of endorsed items (spiritual and } \\
\text { non-spiritual) }\end{array}$ & 0.90 & 0.77 to 1.04 \\
\hline
\end{tabular}

of identifying the patient's specific needs to adequately relieve their distress at the end of life, thus emphasising the importance of the distinction of the different needs-for example, spiritual, psychosocial and physical. This study shows that our participants recognised the spiritual items described in the literature but they also considered psychosocial items to be part of spirituality, and many may be aware they do not differentiate between them in practice, as shown by the fact that more than half of the physicians reported not having differentiated between psychosocial and spiritual needs of the last resident who died. The analysis of the qualitative data also reflects this: it shows that the physicians paid attention to different aspects of spirituality but also shows the challenge for physicians to distinguish between spiritual distress and possible psychological distress. Therefore, physicians' training in distinguishing between spiritual, psychosocial and other needs of nursing home residents at the end of life may contribute to meeting their specific needs in multidisciplinary collaboration. We departed from a conceptualisation of the difference between spiritual and non-spiritual care in the literature. However, the relationship between spiritual and non-spiritual needs, specifically psychosocial needs, may be more complex in reality. For example, in some cases (psychosocial) matters of fear, dependency and healing relationships can be considered to be spiritual matters related to ability to let go and trust, and forgive or receive forgiveness. 
Religiosity, as measured with the Religious and Spiritual Beliefs and Practices Scale, was associated with the physicians' reports of having provided spiritual end-oflife care. More religious physicians may be more cognisant regarding spiritual end-of-life caregiving, as religious aspects of spirituality play an important role in their personal lives.

As end-of-life care for Dutch nursing home residents is mostly provided by on-staff elderly care physicians, they are also responsible for the contents of the resident's care plan, which should contain all the needs of the resident including spiritual needs at the end of life. Within the nursing home setting there have not been significant changes in policy or practice. The current national curriculum for elderly care physicians in training has been in place since 2007 but attention for spiritual care is still very limited. However, since a new guideline on spiritual care in palliative care was published in September 2018, the following changes in training and policy have been promoted: (1) since October 2018 a new policy makes it possible to provide spiritual care in primary care at home; (2) empowerment of healthcare chaplains as spiritual care specialists within the multidisciplinary team; and (3) training of other professionals and volunteers to attend to patients' spiritual needs is currently being developed and tested for effectiveness. Physicians who had 2 years of additional training in palliative care (with attention to all the domains of palliative care including spiritual care) reported significantly more frequently that they provided spiritual end-of-life care, independent of their score on the Religious and Spiritual Beliefs and Practices Scale or having a current religious denomination. The regular palliative care curriculum in the training for elderly care physicians may be supplemented with learning to distinguish spiritual, psychosocial and other needs, and multidisciplinary collaboration on the specific needs of the residents. It may also include attending to spirituality and spiritual caregiving in the form of reflecting on the perception of spirituality of the physician in relation to their spiritual caregiving. Although severe dementia was the reason for some not to provide spiritual care, nearly $40 \%$ of physicians who had provided spiritual care had done so for a patient with dementia (ie, it is commonly encountered). Therefore, spiritual caregiving to people with dementia is an area that could be specifically highlighted in training. Benefits of extending training in spiritual care at the end of life as part of palliative care also involve a focus on what can be done rather than on withholding of medical treatment only.

\section{Limitations of study}

Further research should indicate whether our findings can be generalised to other settings and other specialities. The response (47.2\%) was not high, but around half is common for physician survey studies. ${ }^{28}$ We had no data on the demographics of the members of the professional organisation with which to compare, but the response was not selective with regard to geographical distribution. The pre-structured item 'In your opinion, spirituality at the end of life may comprise ...' may have been inviting and resulted in a relatively high number of items included as belonging to spirituality. The physicians' perception of their provision of spiritual care is subjective and may differ from the reality experienced by the resident or family. Possible differences in perceptions need further study. Furthermore, although 93.5 physicians care for five or more dying patients in a year, ${ }^{29}$ the last resident may, for some physicians, have been a long time ago and the response less precise. Although the structure of care provision in nursing homes differs between countries, our findings may be relevant for multidisciplinary teams involved in the care of nursing home residents outside the Netherlands.

\section{CONCLUSION}

Most physicians included non-spiritual issues in their perception of spiritual end-of-life care and such broader perception increased self-reported spiritual caregiving. Religious physicians and those trained in palliative care may feel fewer barriers to providing spiritual care. Additional training of physicians in reflecting on their own perception of spirituality, distinguishing spiritual and other needs at the end of life, and training in paying attention to the residents' fear of death and dying and multidisciplinary spiritual caregiving may contribute to the quality of end-of-life care for nursing home residents.

Acknowledgements We would like to thank all participating physicians.

Contributors All authors contributed to the development of the questionnaire. Data were collected by MJHEG, analysed by MJHEG and JTvdS, and all authors contributed to data interpretation. MJHEG wrote the first draft of the paper and all authors revised subsequent drafts.

Funding This research was supported by the Pieter van Foreest Stichting, the Iona Stichting, the Department of General Practice \& Elderly Care Medicine and the Department of Public and Occupational Health of the VU University Medical Center, Amsterdam Public Health Research Institute, Amsterdam, the Netherlands.

Competing interests None declared.

Patient consent for publication Not required.

Ethics approval Medical Ethics Review Committee of the VU University Medical Center Amsterdam, the Netherlands, number 2010/157.

Provenance and peer review Not commissioned; externally peer reviewed.

Data sharing statement De-indentified participant data are available upon reasonable request.

Open access This is an open access article distributed in accordance with the Creative Commons Attribution Non Commercial (CC BY-NC 4.0) license, which permits others to distribute, remix, adapt, build upon this work noncommercially, and license their derivative works on different 
terms, provided the original work is properly cited, appropriate credit is given, any changes made indicated, and the use is noncommercial. See: http://creativecommons.org/licenses/by-nc/4. $0 /$.

\section{REFERENCES}

1 World Health Organization. WHO definition of palliative care. Available: https://www.who.int/cancer/palliative/definition/en/ [Accessed January 2019].

2 Puchalski C, Ferrell B, Virani R, et al. Improving the quality of spiritual care as a dimension of palliative care: the report of the consensus Conference. J Palliat Med 2009;12:885-904.

3 Hills J, Paice JA, Cameron JR, et al. Spirituality and distress in palliative care consultation. J Palliat Med 2005;8:782-8.

4 Block SD. Perspectives on care at the close of life. psychological considerations, growth, and transcendence at the end of life: the art of the possible. JAMA 2001;285:2898-905.

5 Cohen SR, Mount BM, Tomas JJ, et al. Existential well-being is an important determinant of quality of life. Evidence from the McGill quality of life questionnaire. Cancer 1996;77:576-86.

6 Edwards A, Pang N, Shiu V, et al. The understanding of spirituality and the potential role of spiritual care in end-of-life and palliative care: a meta-study of qualitative research. Palliat Med 2010;24:753-70.

7 Phelps AC, Lauderdale KE, Alcorn S, et al. Addressing spirituality within the care of patients at the end of life: perspectives of patients with advanced cancer, oncologists, and oncology nurses. J Clin Oncol 2012;30:2538-44.

8 Mitchell SL, Teno JM, Miller SC, et al. A national study of the location of death for older persons with dementia. J Am Geriatr Soc 2005;53:299-305.

9 Davies S, Seymour J. Historical and policy contexts. In: Hockley J, Clark D, eds. Palliative care for older people in care homes. Buckingham: Open University Press, 2002: 4-33.

10 Broad JB, Gott M, Kim H, et al. Where do people die? An international comparison of the percentage of deaths occurring in hospital and residential aged care settings in 45 populations, using published and available statistics. Int J Public Health 2013;58:257-67.

11 Wallace M, O'Shea E. Perceptions of spirituality and spiritual care among older nursing home residents at the end of life. Holist Nurs Pract 2007;21:285-9.

12 Daaleman TP, Williams CS, Hamilton VL, et al. Spiritual care at the end of life in long-term care. Med Care 2008;46:85-91.

13 Gijsberts M-JHE, van der Steen JT, Muller MT, et al. Spiritual end-of-life care in Dutch nursing homes: an ethnographic study. J Am Med Dir Assoc 2013;14:679-84.

14 van der Steen JT, Radbruch L, Hertogh CMPM, et al. White paper defining optimal palliative care in older people with dementia: a Delphi study and recommendations from the European association for palliative care. Palliat Med 2014;28:197-209.
15 Schols JMGA, Crebolder HFJM, van Weel C. Nursing home and nursing home physician: the Dutch experience. J Am Med Dir Assoc 2004;5:207-12.

16 Koopmans RTCM, Lavrijsen JCM, Zuidema SU. The physician's role in nursing homes: the Dutch solution. Arch Intern Med 2010;170:1406-7.

17 Hoek JF, Ribbe MW, Hertogh CM, et al. The specialist training program for nursing home physicians: a new professional challenge. J Am Med Dir Assoc 2001;2:326-30.

18 Gijsberts MJ, van der Steen JT, Muller MT, et al. Spiritual end-of-life care in nursing homes: an exploratory study among physicians. In: Gijsberts MJ, ed. Spiritual care at the end of life in Dutch nursing homes. Amsterdam: VU University Press, 2015: 43-58.

19 Gijsberts M-JHE, Echteld MA, van der Steen JT, et al. Spirituality at the end of life: conceptualization of measurable aspects-a systematic review. J Palliat Med 2011;14:852-63.

20 Miyashita M, Morita T, Sato K, et al. Good death inventory: a measure for evaluating good death from the bereaved family member's perspective. J Pain Symptom Manage 2008;35:486-98.

21 Hungelmann J, Kenkel-Rossi E, Klassen L, et al. Focus on spiritual well-being: harmonious interconnectedness of mindbody-spirit--use of the JAREL spiritual well-being scale. Geriatr Nurs 1996;17:262-6.

22 Steinhauser KE, Clipp EC, Bosworth HB, et al. Measuring quality of life at the end of life: validation of the QUAL-E. Palliat Support Care 2004;2:3-14.

23 Hermann C. Development and testing of the spiritual needs inventory for patients near the end of life. Oncol Nurs Forum 2006;33:737-44.

24 Byock IR, Merriman MP. Measuring quality of life for patients with terminal illness: the Missoula-VITAS quality of life index. Palliat Med 1998;12:231-44.

25 Rainbird KJ, Perkins JJ, Sanson-Fisher RW. The needs assessment for advanced cancer patients (NA-ACP): a measure of the perceived needs of patients with advanced, incurable cancer. A study of validity, reliability and acceptability. Psychooncology 2005;14:297-306.

26 Daaleman TP, Frey B. Spiritual and religious beliefs and practices of family physicians: a national survey. J Fam Pract 1999;48:98-104.

27 Rodin G, Lo C, Mikulincer M, et al. Pathways to distress: the multiple determinants of depression, hopelessness, and the desire for hastened death in metastatic cancer patients. Soc Sci Med 2009;68:562-9.

28 Asch DA, Jedrziewski MK, Christakis NA. Response rates to mail surveys published in medical journals. J Clin Epidemiol 1997;50:1129-36.

29 van der Steen JT, Galway K, Carter G, et al. Initiating advance care planning on end-of-life issues in dementia: ambiguity among UK and Dutch physicians. Arch Gerontol Geriatr 2016;65:225-30. 